\title{
KOMPOSISI HASIL TANGKAPAN DAN UKURAN LOBSTER DENGAN JARING INSANG DI PERAIRAN KABUPATEN ACEH JAYA
}

\author{
Catch Composition And Size Of Lobster Wish Gillnet In Aceh Jaya Waters \\ Oleh: \\ Irfannur $^{1^{*}}$, Ronny Irawan Wahju ${ }^{2}$, Mochammad Riyanto ${ }^{2}$ \\ ' Mahasiswa Program Studi Teknologi Perikanan Laut \\ 2 Staf pengajar Program Studi Teknologi Perikanan Laut \\ *Korespondensi: irfannur.ramli@gmail.com
}

\begin{abstract}
ABSTRAK
Kabupaten Aceh Jaya memiliki potensi perikanan lobster yang cukup potensial untuk dikembangkan menjadi komoditi unggulan perikanan. Terdapat 6 spesies lobster yang bernilai ekonomis tinggi di perairan Aceh Jayayaitu Panulirus homarus, $P$. longipes, $P$. ornatus, $P$. penicillatus, $P$. polyphagus dan $P$. versicolor.Tujuan penelitian adalahmenganalisis komposisi jenis dan distribusi ukuran hasil tangkapan lobster di perairan Aceh Jaya, mengetahui hubungan panjang dan berat lobster dikaitkan dengan panjang karapas pertama kali matang gonad (CLM) dan aturan yang ada, dan mengestimasi produktivitas penangkapan lobster dengan jaring insang (gillnet) di perairan Aceh Jaya. Pengumpulan data dilakukan dengan survei lapang di lokasi pendaratandan tempat pengumpulan lobster padabulan Januari-Febuari tahun 2016 di Kabupaten Aceh Jaya. Komposisi hasil tangkapan gillnet lobster didominasi oleh $P$. penicillatussebanyak $31.41 \%$, diikuti oleh $P$. homarus sebanyak $27.92 \%$, $P$. longipes sebanyak $22.17 \%, P$. versicolor sebanyak $11.97 \%$ dan $P$. ornatus sebanyak $4.68 \%$. Pola hubungan panjang dan berat ke lima jenis lobster yang tertangkap bersifat allometrik negatif. Hasil tangkapan lobster yang layak tangkap berkisar antara $56.66-100 \%$, jika dibandingkan dengan PERMEN-KP No 56 tahun 2016 dengan ukuran legal tangkap diatas $8 \mathrm{~cm}$ sebesar60.00 - 90,00\%. Produktivitas penangkapan lobster menggunakan gillnet terjadi pada bulan April sebesar $2.440 \mathrm{~kg} /$ trip dan terendah pada bulan Januari sebesar $1.330 \mathrm{~kg} /$ trip.
\end{abstract}

Kata kunci: jaring insang, lobster, panulirus, produktivitas penangkapan.

\section{ABSTRACT}

Aceh Jaya Regency is a potential area for development of lobster fishery. There are six species of lobster with high economic value in Aceh Jaya such asPanulirus homarus, P. longipes, P. ornatus, $P$. penicillatus, P.polyphagus and P. versicolor. Theobjectives ofthis research areto analyze the species composition and size distribution of lobster catch, to determine the relationship of length and weight of lobster and associated with Carapace Length Maturity (CLM) and existing regulation, to estimate catch productivity of lobster from gillnet fishery.Data was collected by using survey method in January to Febuary 2016 in Aceh Jaya waters. The catch composition of gillnet was dominated by $P$. penicillatuswith total $31.41 \%$, followed by $P$. homarus was $27.92 \%$, P. longipes was $22.17 \%, P$. versicolor was $11.97 \%$, and $P$. ornatuswas $4.68 \%$ in respectively. The length and weight relationship of five species lobster were caught in Aceh Jaya waters showed a allometric negative growth 56.66$100 \%$ of lobster were above CLM reference, comparing to existing regulation (PERMEN-KP No 56/2016) with the legal catch over $8 \mathrm{~cm}$ in the range of60.00-90.00\%. The highest catch productivityofgillnet was found in April with the weight about $2.440 \mathrm{~kg} /$ trip and the lowest catch productivity was in January with the weight about $1.330 \mathrm{~kg} /$ trip.

Keywords : catch productivity, gillnet, lobster, panulirus. 


\section{PENDAHULUAN}

Kabupaten Aceh Jayaterletak di pantai barat selatan yang berhadapan langsung dengan Samudera Hindia. Wilayah ini memiliki potensi perikanan lobster yang cukup potensial untuk dikembangkan menjadi komoditi unggulan perikanan. Produksi total hasil tangkapan lobster Kabupaten Aceh Jaya pada tahun 2011-2014sebesar 382.4 ton atau 39.16\% dari total produksi Provinsi Aceh(DKP Aceh 2016). Pemanfaatan lobster sebagian besar berasal dari kegiatan penangkapan dengan menyelam dan menggunakan alat tangkap jaring insang dengan teknologi yang masih tradisional (DKP Aceh 2012).

Berdasarkan hasil identifikasi hasil tangkapan yang didaratkan dan penelitian terdahulu, terdapat enam spesies lobster di Aceh Jaya yaitu lobster pasir (Panulirus homarus) (Kembaren \& Nurdin 2015), lobster bintik/batik (Panulirus longipes)(Dall 1974), lobster mutiara/maradona (Panulirus ornatus)(Yusnaini et al. 2009), lobster batu (Panulirus penicillatus)(Chang et al. 2007), lobster pakistan (Panulirus polyphagus)(Ikhwanuddin et al. 2014), dan lobster bambu (Panulirus versicolor)(Page 2013). Jenis lobster tersebut diidentifikasi secara random pada bulan Agustus 2007September 2008 disekitar lokasi pendaratan di Lhok Kruet Kabupaten Aceh Jaya, Provinsi Aceh(Tewfik et al.2009). Jenis lobster tersebut memiliki nilai jual yang tinggi dan menjadi komoditas ekspor,sehingga nelayan melakukan penangkapan secara cukup intensif (Saputra 2009). Kegiatan penangkapan lobster di wilayah ini,sebagian besar dilakukan dengan alat tangkap jaring insang(gillnet) jenis monofilament. Penggunaan alat tangkap gillnet ini disebabkan karena memiliki jumlah hasil tangkapan yang lebih banyak dibandingkan dengan jaring krendet (trap net) (Febriani et al. 2014).

Pemanfaatan lobster di Kabupaten Aceh Jaya masih menghadapi permasalahan antara lain: masih terbatasnya informasi dari stakeholder terkait tentang usaha penangkapan lobster, terbatasnya informasi tentang kondisi biologi lobster yang tertangkap seperti tingkat kematangan gonad, komposisi ukuran panjang dan berat, serta terbatasnya data dan informasi tentang produktivitas alat tangkap gillnet untuk menangkap lobster. Berdasarkan hal tersebut masih sangat diperlukan penelitian tentang produktivitas penangkapan dan karakteristik hasil tangkapan lobster di Aceh Jaya dalam rangka pengelolaan perikanan lobster yang berkelanjutan.

Pemerintah pada tahun 2015 mengeluarkan aturan penangkapan lobster, kepiting dan rajungan dalam kondisi bertelur dan pembatasan ukuran panjang karapas lobster di atas $8 \mathrm{~cm}$ (PERMEN-KP No 1 tahun 2015 diperbaharui menjadi PERMEN-KP No 56 tahun 2016). Diterbitkannya aturan tersebut menjadi salah satu acuan dalam penangkapan lobster yang ada di Kabupaten Aceh Jaya. Penelitian ini juga membahas hubungan antara ukuran lobster yang tertangkap dikaitkan dengan panjang lobster pertama kali matang gonad (LM) dengan aturan tersebut, untuk melihat seberapa besar perbedaan lobster yang dapat dimanfaatkan oleh nelayan dengan aturan yang ada. Tujuan penelitian ini adalah 1) menganalisis komposisi jenis dan distribusi ukuran hasil tangkapan lobster di perairan Aceh Jaya,2) mengetahui hubungan panjang dan berat lobster dikaitkan dengan panjang Carapace Length Maturity(CLM) referensi dan aturan yang ada, dan 3) mengestimasi produktifitas penangkapan lobster dengan alat tangkap jaring insang (gillnet) di perairan Aceh Jaya.

\section{METODE PENELITIAN}

Penelitian ini dilakukan pada bulan Januari-Febuari 2016 di perairan Aceh Jaya (Gambar 1). Secara geogafis terletak di antara $4^{\circ} 37^{\prime}$ 59.505" N dan 95³3' 33.248" E. Pengumpulan data dilakukan dengan survei lapangan di lokasi pendaratan dan tempat pengumpul lobster di Lhok Rigaih, Kabupaten Aceh Jaya. Pengumpulan data primer dilakukan selama dua bulan yaitu pada bulan Januari hingga Februari, sedangkan pengumpulan data sekunder berupa data hasil tangkapan lobster dilakukan selama 12 bulan dari bulan November 2015 hingga Oktober 2016. 


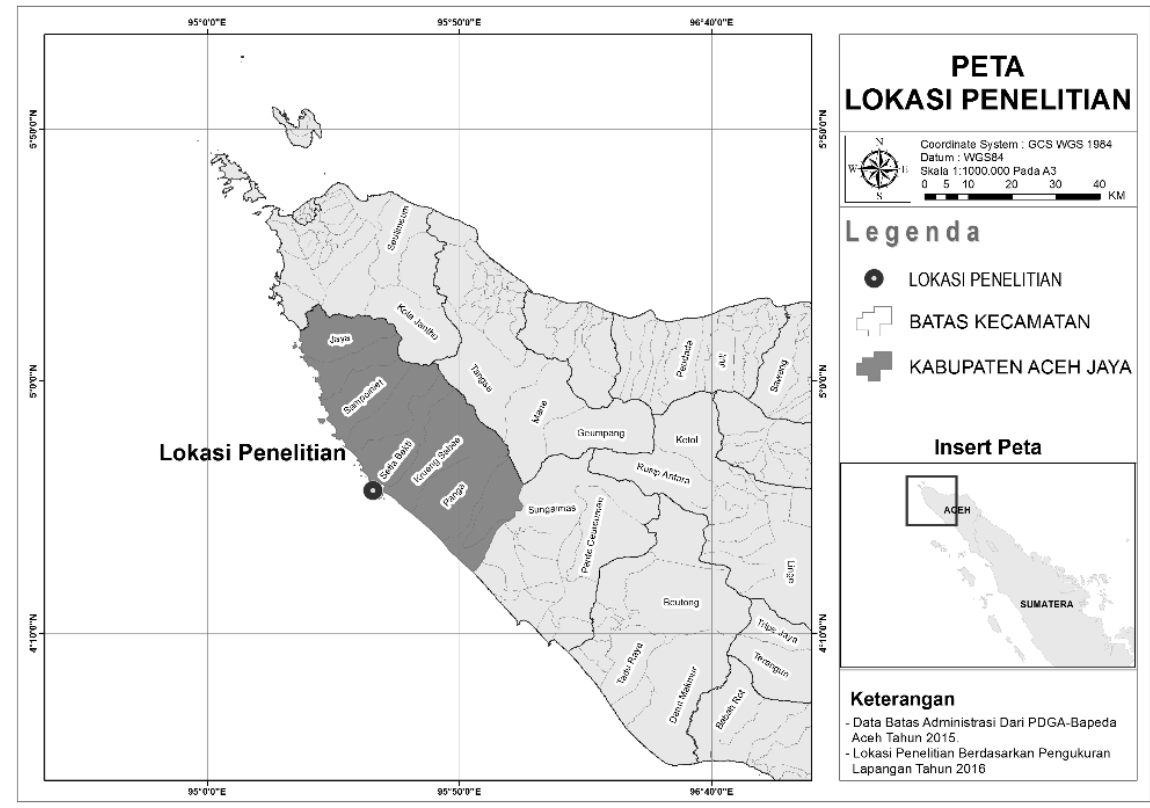

Gambar 1 Peta lokasi penelitian

Data primer yang dikumpulkan adalah jenis lobster yang diidentifikasi menggunakan buku identifikasi lobster (Houlthuis 1991). Pengukuran panjang dan berat dilakukan dengan menggunakan penggaris dan timbangan digital. Pengukuran panjang lobster dilakukan dengan mengukur panjang kerapas (PK), panjang badan (PB) dan panjang total (PT) dengan satuan mm. Pengukuran panjang karapas dilakukan dengan cara mengukur panjang dari tepi post orbital sampai ujung posterior karapasnya, sesuai petunjuk Sparre dan Venema (1999). Data sekunder berupa catatan hasil tangkapan lobster per bulan di lokasi pendaratan Lhok Rigaih, daerah penangkapan dan keragaan unit penangkapan gillnet lobster dengan menggunakan wawancara dengan nelayan.
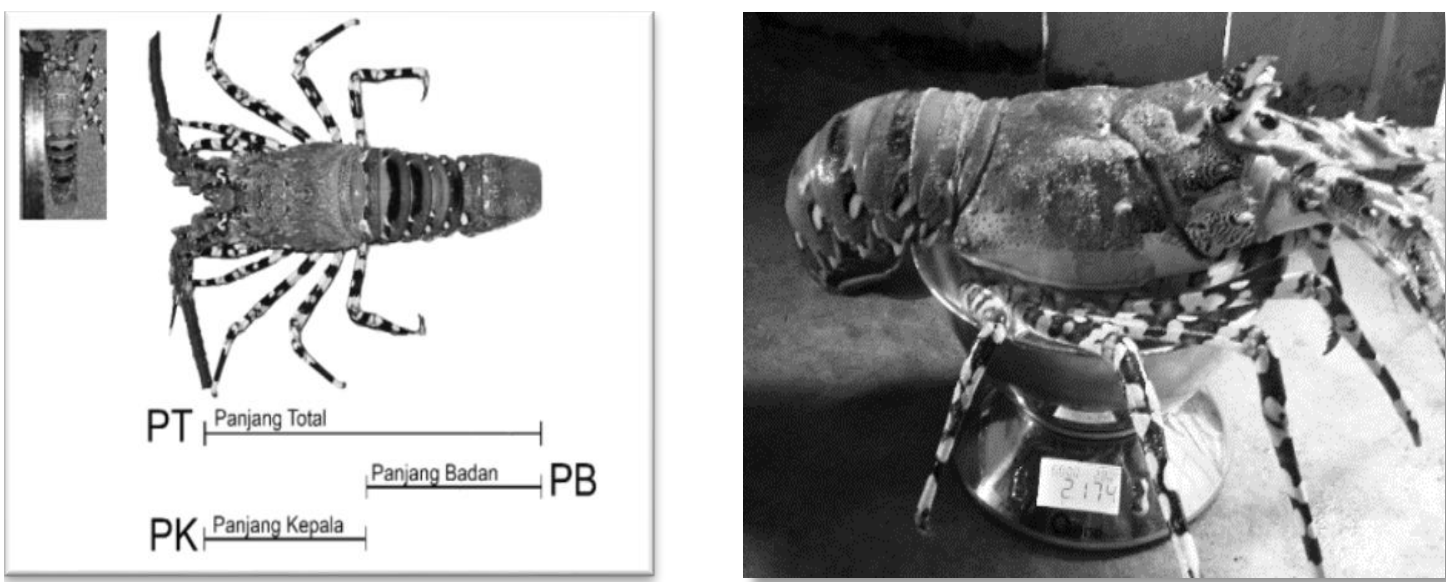

Gambar 2 Pengukuran panjang dan berat lobster

Pengambilan sampel untuk menghitung komposisi dan distribusi ukuran hasil tangkapan lobster dilakukan selama 2 bulan dengan jumlah sampel yang diukur sebanyak 3.220 ekor. Pengambilan data panjang dan berat dilakukan dengan mengukur setiap jenis lobster ( $P$. penicillatus, $P$. homarus, $P$. longipes, $P$. versicolor dan $P$. ornatus) yang tertangkap selama 11 hari. Jumlah lobster yang diukur panjang dan beratnya adalah sebanyak 457 ekor. Hasil pengukuran panjang dan berat selanjutnya dianalisis distribusi ukuran dan hubungan panjang berat lobster. Analisis data yang dihitung yaitu komposisi hasil tangkapan, hubungan panjang berat dan produktifitas penangkapan. 


\section{Komposisi Hasil Tangkapan}

Analisis komposisi hasil tangkapan dilakukan secara deskriptif-tabulatif. Komposisi hasil tangkapan lobster disajikan dalam bentuk grafik komposisi hasil tangkapan untuk seluruh hasil tangkapan lobster. Data ukuran panjang dan berat hasil tangkapan lobster disajikan dalam bentuk tabel dan grafik distribusi ukuran untuk setiap jenis lobster.

2. Hubungan Panjang Berat

Analisis hubungan panjang dan beratdihitung menggunakan persamaan hubungan panjang dan berat (Bal \& Rao 1984), sebagai berikut:

$$
\mathrm{W}=a L^{b}
$$

Dimana $W$ adalah berat lobster (g), $L$ adalah panjang karapas (mm), a adalah konstanta dan $b$ adalah nilai eksponensial (antara 2 - 5). Berdasarkan persamaan tersebut dapat diketahui pola pertumbuhan panjang dan bobot ikan. Nilai $b$ yang diperoleh digunakan untuk menentukan pola pertumbuhan, uji-t untuk nilai $b$ yang diperoleh pada selang kepercayaan 95\% $(a=0,05)$ (Goddard 1996). Persamaan ini dapat diselesaikan melalui transformasi linear logaritma dalam bentuk:

$$
\log W=\log a+b \log L .
$$

Dengan demikian persamaan ini dapat diselesaikan seperti menyelesaikan persamaan linear biasa. Hasil dari perhitungan hubungan panjang-berat, lalu diintepretasikan. Bila nilai $b$ sama dengan 3 menunjukkan bahwa pertumbuhan lobster tidak berubah bentuknya.

Analisis hubungan panjang berat juga dikaitkan dengan CLM berdasarkan sumber referensi untuk setiap jenis lobster dan dikaitkan dengan PERMEN-KP No 56 tahun 2016 Pasal 2 (b), penangkapan lobster (Panulirus spp) dapat dilakukan dengan ukuran panjang karapas $>8 \mathrm{~cm}$. Perbandingan ukuran panjang dan berat lobster dihitung persentase antara CLM dengan aturan pemerintah, dan disajikan dalam gambar serta tabel perbandingan untuk setiap jenis lobster yang tertangkap di lokasi penelitian.

\section{Produktifitas Penangkapan}

Produktivitas penangkapan lobster dengan alat tangkapgillnetdilakukan dengan menghitung hasil tangkapan lobster tiap upaya penangkapan (Catch per Unit Effort atau CPUE). Analisis ini dilakukan untuk mengetahui kelimpahan dan tingkat pemanfaatan yang didasari atas pembagian antara total hasil tangkapan (Catch) dengan upaya penangkapan (Effort) dengan persamaan menurut Sparre dan Venema (1999) yaitu:

$$
C P U E=\frac{C}{F}
$$

Keterangan: $C P U E=$ Hasil tangkapan per upaya (kg/trip)

Catch $(C)=$ Total hasil tangkapan $(\mathrm{kg})$

$\operatorname{Effort}(F)=$ Total upaya penangkapan (trip)

\section{HASIL DAN PEMBAHASAN}

\section{Hasil}

1. Komposisihasil Tangkapan Lobster

Jumlah hasil tangkapan di Lhok Rigaih selama bulan Januari-Febuari 2016 dengan alat tangkap gillnet didominasi oleh jenis $P$. penicillatus sebanyak 1.034 ekor (31.41\%), kemudian $P$. homarus sebanyak 919 ekor (27.92\%), P. longipessebanyak 730 ekor (22.17\%), P. versicolorsebanyak 394 ekor (11.97\%), $P$. ornatussebanyak 154 ekor(4.68\%), Parribacus antarticussebanyak 58 ekor (1.76\%) dan $P$. 
polyphagus sebanyak 3 ekor (0.09\%) secara berturut-turut. Komposisi berat masing-masing jenis lobster yang tertangkap di Lhok Rigaih didominasi oleh $P$. penicillatus dengan persentase $34.20 \%$, kemudian diikuti jenis $P$. homarus (25.96\%), P. longipes (20.12\%), P. versicolor (13.03\%), P. ornatus (5.62\%), Parribacus antarticus (1.01\%) dan P. polyphagus (0.07\%) (Gambar 3$)$.

\section{a. komposisi jumlah}

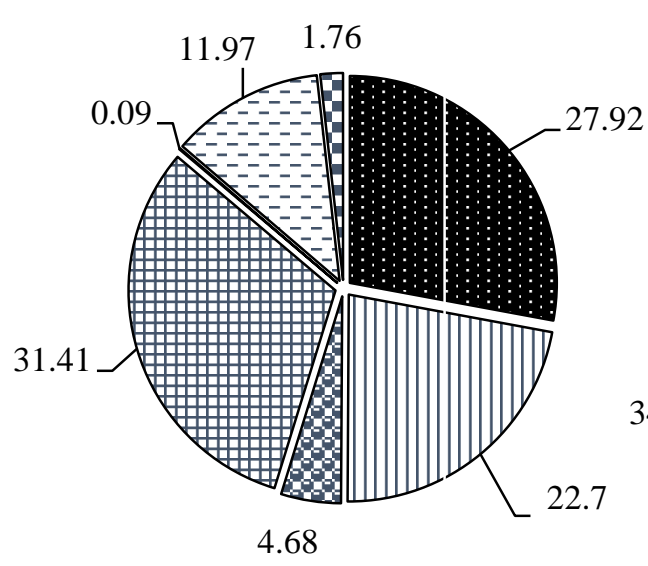

4.68

\section{b. komposisi berat}

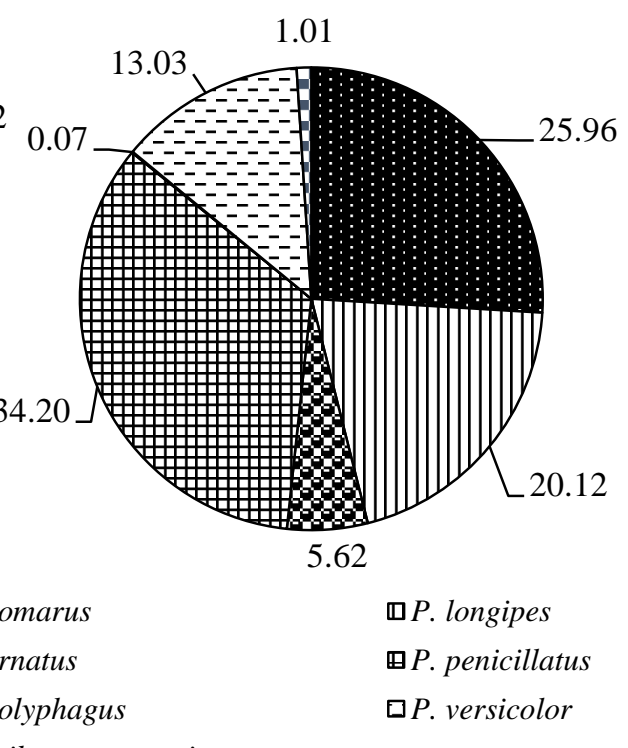

๑arribacus antarcticus

Gambar 3 Komposisi jumlah (a) dan berat (b)hasil tangkapan lobster di lokasi penelitian

\section{Distribusi Ukuran Hasil Tangkapan}

Berdasarkan 5 jenis hasil tangkapan lobster, distribusi hasil tangkapan dilakukan per jenis lobster untuk melihat sebaran ukuran hasil tangkapan. Tiga jenis lobster yaitu $P$. penicillatus, $P$. homarus, dan $P$. longipestertangkap pada selang bobot 250-299g (Gambar 4). Rerata distribusi ukuran hasil tangkapan lobsterjenis $P$. penicillatusadalah $314 \pm 4.7 \mathrm{~g}$, kemudian jenis $P$. homarussebesar $276 \pm 3.8 \mathrm{~g}, P$. longipessebesar $268 \pm 4.2 \mathrm{~g}$, $P$. versicolor sebesar $321 \pm 7.4 \mathrm{~g}$ dan $P$. ornatussebesar $356 \pm 14.2 \mathrm{~g}$.

\section{Hubungan Panjang Berat Lobster}

Jumlah individu hasil tangkapan yang diambil sebagai sampel selama 11 hari sebanyak 457 ekor. Hasil tangkapan didominasi oleh jenis $P$. homarus sebanyak 140 ekor dengan bobot $30.465 \mathrm{~g}, P$. longipes sebanyak 130 ekor dengan bobot $30.736 \mathrm{~g}$, $P$. penicillatus sebanyak 77 ekor dengan bobot $25.757 \mathrm{~g}, P$. versicolor sebanyak 73 ekor dengan bobot $21.185 \mathrm{~g}$ dan $P$. ornatus sebanyak 30 ekor dengan bobot $9.753 \mathrm{~g}$ (Tabel 1).

Hubungan panjang berat $P$. homarus diperoleh nilai $b=2.661$, persamaan hubungan panjang berat adalah $W=0.001 L^{2.661}$. $P$. longipes hubungan panjang berat diperoleh nilai $b=1.885$, persamaan hubungan panjang berat adalah $W=0.053 L^{1.885}$. $P$. penicillatus hubungan panjang berat diperoleh nilai $b=2.087$, persamaan hubungan panjang berat adalah $W=0.025 L^{2.087} . P$. versicolor hubungan panjang berat $P$ diperoleh nilai $b=2.415$, persamaan hubungan panjang berat adalah $W=0.0057 L^{2.415}$. $P$. ornatus hubungan panjang berat diperoleh nilai $b=2.310$, persamaan hubungan panjang berat $W=$ $0.008 L^{2.310}$. 

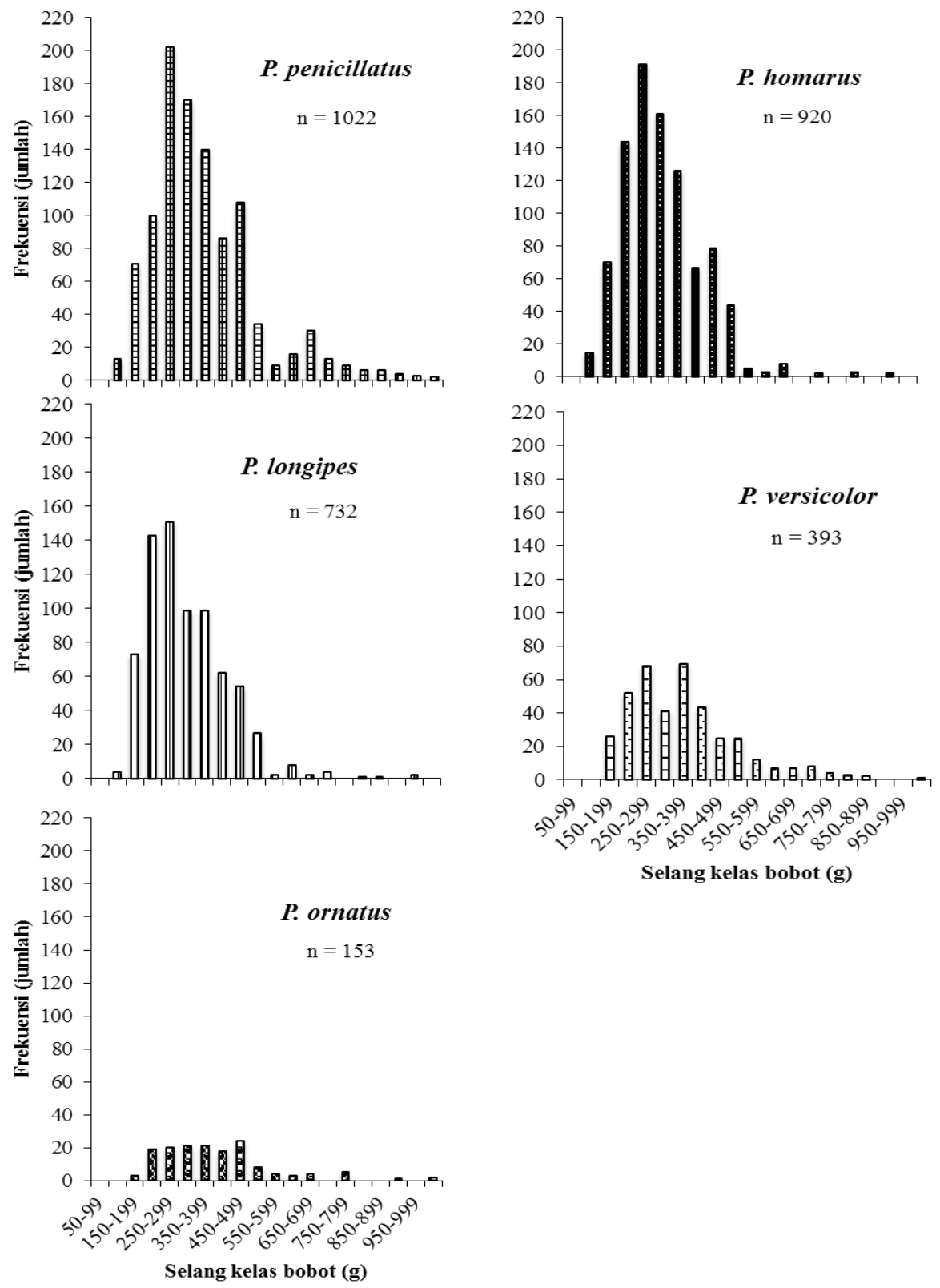

Selang kelas bobot $(g)$

Gambar 4 Distribusi ukuran berat untuk lima jenis

Tabel 1 Komposisi hasil tangkapan lobster selama sampling di Lhok

\begin{tabular}{lcccc}
\hline \multirow{2}{*}{ Spesies } & \multicolumn{4}{c}{ Persentase (\%) } \\
\cline { 2 - 5 } & Jumlah & Berat $(\mathrm{g})$ & Jumlah & Berat \\
\hline Panulirus homarus & 140 & 30.465 & 30.63 & 25.62 \\
Panulirus longipes & 130 & 30.736 & 28.45 & 25.85 \\
Panulirus penicillatus & 77 & 25.757 & 16.85 & 21.66 \\
Panulirus versicolor & 73 & 21.185 & 15.97 & 17.82 \\
Panulirus ornatus & 30 & 9.753 & 6.56 & 8.20 \\
Panulirus polyphagus & 2 & 404 & 0.44 & 0.34 \\
Parribacus antarcticus & 5 & 601 & 1.09 & 0.51 \\
Total & 457 & 118.901 & 100.00 & 100.00 \\
\hline
\end{tabular}


Berdasarkan uji statistik tidak terdapat perbedaan nyata dari persamaan hubungan panjangberat untuk kelima jenis lobster tersebut. Uji-t pada taraf nyata 95\% dari nilai $b$ terhadap nilai 3 untuk kelima jenis lobster diperoleh thitung (54.163) >ttabel (1.835). Dengan demikian maka dari kelima jenis lobster $P$. homarus, $P$. longipes, $P$. penicillatus, $P$. versicolor dan $P$. ornatus diterima nilai $\mathrm{b}<3$ (allometrik negatif) yang berarti pertambahan panjang pada jenis lobster tersebut lebih cepat dari pada pertambahan beratnya (Gambar 5).

Selanjutnya hubungan panjang karapas dan berat lobster di Kabupaten Aceh Jaya dikaitkan dengan penelitian CLM terdahulu sebagai referensi dan Peraturan Menteri Kelautan dan Perikanan Republik Indonesia Nomor 56/PERMEN-KP/2016 (Gambar 5). Hal ini dilakukan untuk mengetahui persentasi jumlah lobster yang layak tangkap. Persentase perbandingan panjang karapas lobster yang tertangkap disajikan pada Tabel 2.
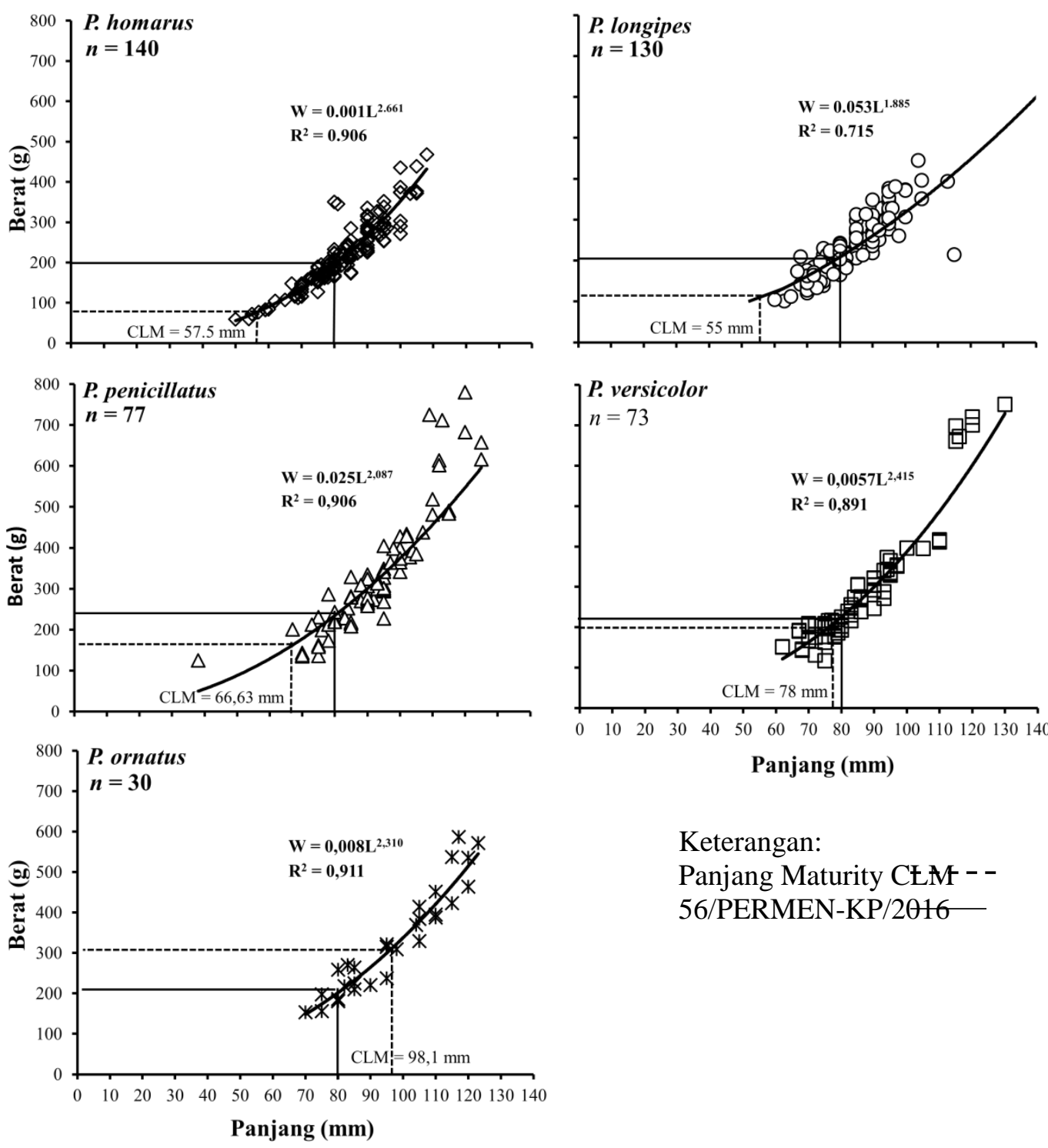

Panjang (mm)

Keterangan:

Panjang Maturity CEAF - -

56/PERMEN-KP/2016

Gambar 5 Hubungan antara panjang karapas dan berat lobsterdikaitkan dengan peraturan pemerintah tentang ukuran yang diperbolehkan. Garis penuh merupakan aturan Permen Kelautandan Perikanan (56/PERMEN-KP/2016), garis terputus merupakan panjang karapas maturity (CLM) berdasarkan referensi. 
Tabel 2 Persentase panjang karapas lobster berdasarkan ukuran panjang lobster pertama kali matang gonad (LM) dan PERMEN-KP No 56 tahun 2016

\begin{tabular}{lcccccl}
\hline \multirow{2}{*}{ Spesies } & $\begin{array}{c}\text { Panjang } \\
\text { karapas CL }\end{array}$ & \multicolumn{2}{c}{ Referensi } & \multicolumn{2}{c}{ 56/PERMEN- } \\
\cline { 3 - 6 } & $(\mathrm{mm})$ & $\begin{array}{c}\text { diatas } \\
(\%)\end{array}$ & $\begin{array}{c}\text { dibawah } \\
(\%)\end{array}$ & $\begin{array}{c}\text { diatas } \\
(\%)\end{array}$ & $\begin{array}{c}\text { dibawah } \\
(\%)\end{array}$ & \\
\hline P. homarus & 57.50 & 97.85 & 2.14 & 60.00 & 40.00 & Kulmiye 2006 \\
P. homarus & 76.80 & 67.85 & 32.14 & 60.00 & 40.00 & Kembaren 2015 \\
P. longipes & 55.00 & 100.00 & 0.00 & 70.00 & 30.00 & Gomez 1994 \\
P. penicillatus & 66.63 & 98.70 & 1.30 & 81.82 & 18.18 & Chang 2007 \\
P. versicolor & 78.00 & 69.86 & 30.14 & 61.64 & 38.36 & Frisch 2007 \\
P. versicolor & 71.00 & 86.30 & 13.70 & 61.64 & 38.36 & Junaidi 2010 \\
P. ornatus & 98.10 & 56.66 & 43.33 & 90.00 & 10.00 & Zakaria 1999 \\
\hline
\end{tabular}

Hasil perbandingan persentase ini menunjukkan bahwa hasil tangkapan setiap jenis lobster berdasarkan ukuran panjang lobster pertama kali matang gonad (LM) dan PERMEN-KP No 56 tahun 2016 mendapatkan persentase yang berbeda. Persentasi ukuran hasil tangkapan dangan LM referensi didapatkan ukuran yang sudah layak tangkap sebesar $56.66-100 \%$. Kemudian hasil perbandingan dengan PERMEN-KP No 56 tahun 2016, persentase hasil tangkapan yang layak tangkap sebesar 60.00-90.00\%. Perbandingan persentase ini menunjukkan bahwa sumberdaya lobster yang ada di Aceh Jaya berdasarkan distribusi hasil tangkapan setiap jenis ukuran panjang lobster pertama kali matang gonad (LM) dan PERMEN-KP No 56 tahun 2016masih layak untuk usaha penangkapan lobster.

4. Produktivitas Hasil Tangkapan Lobster Di Perairan Aceh Jaya

Berdasarkan data yang dihasilkan rata-rata jumlah operasi/trip nelayan per bulan yang di daratkan di Lhok Rigaih selama satu tahun. Produktivitas hasil tangkapan berfluktuasi dari bulanNovember 2015-Oktober 2016. Produktivitastertinggi terjadi pada bulan April $2.440 \mathrm{~kg} /$ trip. Nilai produktivitas terendah terjadi pada bulan Januari sebesar $1.330 \mathrm{~kg} /$ trip.Produktivitas penangkapan lobster per bulan selama satu tahun disajikan pada Gambar 6.

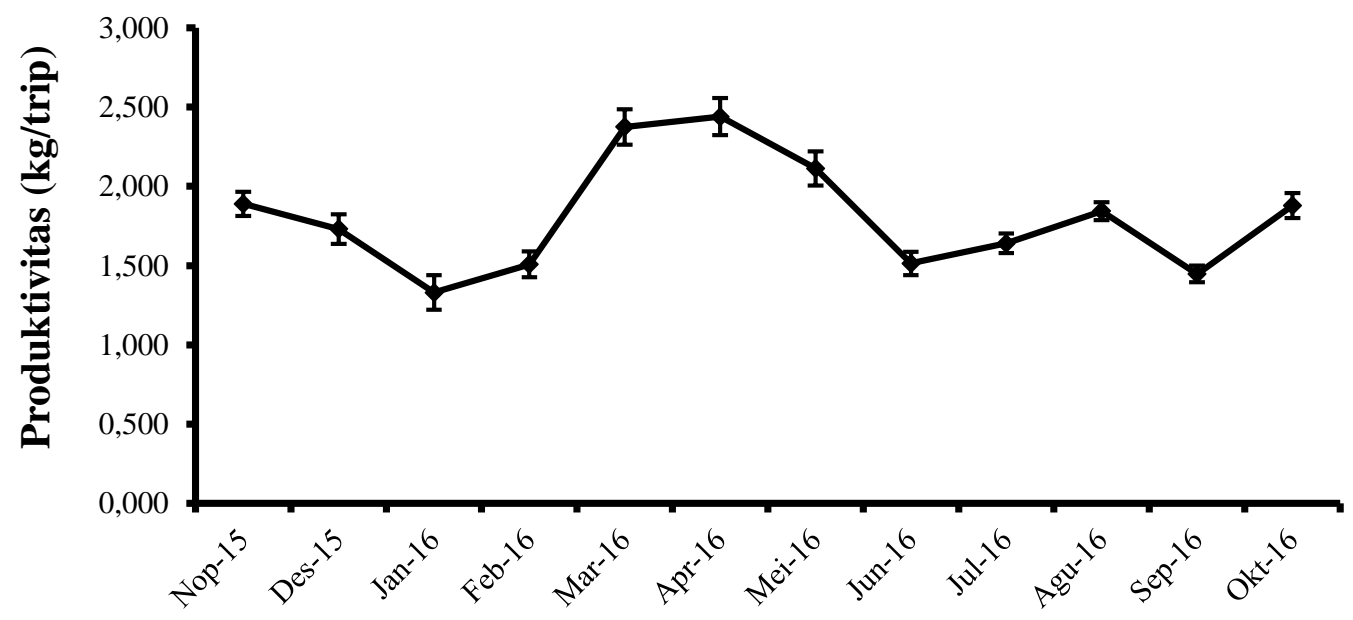

Gambar 6 Fluktuasi produktivitas penangkapanlobster per bulanselama satu tahun (periode November 2015 - Oktober 2016) 


\section{Pembahasan}

Komposisi hasil tangkapan lobster di Kabupaten Aceh Jayadominan adalah jenis lobster batu $P$. penicillatus. Lobster tersebut memiliki ciri-ciri tubuh berwarna biru dan hitam gelap. Lobster jantan berwarna lebih gelap dibanding lobster betina. Abdomen mempunyai bintik-bintik yang tidak jelas serta ujung duri besar pada karapas berwarna kekuning-kuningan. Tangkai antenna terdapat garisgaris putih, flagellium antena berwarna kecoklatan dan pangkal tangkai berwarna biru serta memiliki kaki jalan. Lobster ini hidup pada terumbu karang dengan kedalaman perairan 1-4m dengan kedalaman maksimum $16 \mathrm{~m}$ (Carpenter \& Niem 1998). Lobster jenis $P$. penicillatus dapat hidup berasosiasi dengan jenis $P$. homarus (Suadi et al. 2001), hal ini menyebabkan $P$. homarus juga ikut tertangkap dalam jumlah yang cukup besar yaitu 27.92\%.

Tertangkapnya 5 jenis lobster di Kabupaten Aceh Jaya disebabkan karena lokasi tersebut merupakan lokasi yang potensial untuk penangkapan lobster. Ke lima jenis lobster tersebut hidup dan menyebar hampir diseluruh perairan Indonesia terutama di wilayah yang berbatasan langsung dengan Samudera Hindia seperti pantai Barat Sumatera, Selatan Jawa dan Bali dan Nusa Tenggara. Hasil tangkapan lobster di Perairan Teluk Ekas Pulau Lombok diperoleh 5 spesies lobster yaitu Panulirus homarus, $P$. versicolor, $P$. ornatus, $P$. penicillatus dan P. longipes(Junaidi et al. 2010).Di perairan Kabupaten Cilacap lobster yang tertangkap menggunakan alat tangkap gillnet adalah $P$. ornatus, P. homarusdan P. polyphagus (Mahdiana \& Laurensia 2013).Di perairan selatan Gunung Kidul dan Pacitan, komposisi jenis lobster yang dominan tertangkap yaitu jenis $P$. penicillatus (Fauzi et al. 2013). Hasil tangkapan jaring krendet (trap net) di Pacitan menangkap $P$. penicillatus, $P$. longipesP. versicolodan $P$. polyphagus (Bakhtiar et al. 2014).Hasil tangkapan gillnet lobster di Perairan Palabuhanratu Kabupaten Sukabumi adalah jenis $P$. homarus, $P$. ornatus dan $P$. versicolor (Nevada et al. 2012).

Distribusi ukuran hasil tangkapan tiga jenis lobster yaitu $P$. penicillatus, $P$. homarus dan $P$. longipestertangkap pada selang bobot 250-299g. Ukuran tersebut lebih besar dibandingkan dengan lobster jenis yang dominan tertangkap di perairan selatan Yogyakarta dengan ukuran selang kelas 100-150g (Aisyah \& Triharyuni 2010). Perbedaan ukuran tersebutmemberikan gambaran bahwa lobster yang tertangkap di Kabupaten Aceh Jaya sebagian besar masih layak tangkap,sehingga usaha pemanfaatan lobster masih dapat ditingkatkan.

Pengukuruan panjang dan berat bertujuan untuk mengatahui konversi dan ukuran panjang ke berat atau sebaliknya, digunakan sebagai petunjuk kesehatan, kegemukan, produktivitas dan kondisi fisiologis termasuk perkembangan gonad (Merta1993). Hasil penelitian menunjukkan bahwa pola pertumbuhan ke lima jenis lobster $P$. penicillatus, $P$. homarus, $P$. longipes, $P$. versicolor, dan $P$. ornatus yang tertangkap di Kabupaten Aceh Jaya bersifat allometrik negatif. Hasil penelitian yang menunjukkan pertumbuhan yang allometrik negatif di Pangandaran (Suman et al. 1994), Teluk EkasLombok (Junaidi et al.2010), Aceh (Suman \& Subani 1993) dan Selatan Yogyakarta (Aisyah \& Triharyuni2010). Hubungan panjang berat dari lobster dipengaruhi oleh beberapa faktor seperti umur, bentuk badan, kelamin, musim, suhu, salinitas dan ketersediaan makanan (Moutopoulos \& Stergiou 2002).

Tingkat kematangan lobster (size at maturity) dan ukuran layak tangkap setiap jenis memiliki perbedaan (Chang et al.2007; Suman et al. 1994). Pemerintah melalui Menteri Kelautan dan Perikanan mengeluarkan 56/PERMEN-KP/2016, sebagai upaya pelestarian berbasis ekosistem dalam jangka panjang yang diharapkan dapat berkontribusi penting bagi peningkatan komoditi produksi perikanan lobster di Indonesia. Peraturan tersebut mewajibkan pelepasan kembali spesies laut sepertilobster dan rajungan bertelur serta memberlakukan ukuran layak tangkap untuk memastikan bahwa spesies tersebut telah bereproduksi minimal satu kali untuk memastikan keberlanjutan sumber dayanya (Hilal 2016). 
Peraturan tentang penangkapan lobster (Panulirus spp) pada Pasal 2 (a), dijelaskan bahwa setiap orang dilarang melakukan penangkapan Lobster (Panulirus spp) dalam kondisi bertelur. Kemudian Pasal 2 (b)dijelaskan bahwa Penangkapan Lobster (Panulirus spp) dengan ukuran panjang karapas diatas $8 \mathrm{~cm}$. Berdasarkan hasil penelitian sebelumnya diketahui bahwa ukuran panjang lobster pertama kali matang gonad (LM)setiap jenis lobster memiliki perbedaan. $P$. homarus tingkat kematangan terjadi pada ukuran CLM $57.50 \mathrm{~mm}$ (Kulmiye 2006), pada ukuran di atas $57.50 \mathrm{~mm}$ lobster sudah bisa ditangkap.Demikian juga yang terjadi pada $P$. longipes, $P$. penicillatus dan $P$. versicolor. Perbedaan hanya terjadi pada $P$. ornatusdengan tingkat kematangan terjadi pada ukuran CLM $98.10 \mathrm{~mm}$, jenis ini tidak terpengaruh oleh PERMEN-KP No 56 tahun 2016.Perbedaan ini memunculkan pro dan kontra terhadap aturan tersebut, ukuran layak tangkap seharusnya dibuat per spesies untuk memastikan bahwa tidak terjadi perbedaan ukuranantara lobster yang dapat dimanfaatkan dengan lobster yang dilindungi. Berdasarkan perbedaan CLM antara peraturan dan CLM berdasarkan penelitian, didapatkan perbedaan tingkat pemanfaatan lobster yang dapat ditangkap oleh nelayan di Kabupaten Aceh Jaya. Hasil tangkapan lobster yang belum layak tangkap berkisar antara 10-40\% dari total tangkapan.

Produktivitas penangkapan lobster di Lhok Rigaih selama setahun yang tertinggi sebesar 2.440 $\mathrm{kg}$ /trippada bulan April sedangkan yang terendah sebesar $1.330 \mathrm{~kg} /$ trip pada bulan Januari. Namun demikian, kegiatan penangkapan lobster di Kabupaten Aceh Jaya berlangsung sepanjang tahun. Hal ini terlihat dari produksi tangkapan per bulan setiap tahunnya. Kondisi perairan di Kabupaten Aceh Jaya yang relatif tenang pada saat musim hujan dan angin berhembus dari arah barat laut memudahkan nelayan melakukan operasi penangkapan lobster sepanjang tahun. Selain itu, lokasi penangkapan yang berada dalam teluk dan dilindungi oleh pulau-pulau kecil menyebabkan kegiatan penangkapan dapat dilakukan sepanjang tahun tanpa terpengaruh oleh cuaca (Nurdin et al. 2014).

Musim di perairan laut Provinsi Acehdibagi menjadi empat musim yaitu musim barat (Desember, Januari, Febuari), musim peralihan barat (Maret, April, Mei), musim timur (Juni, Juli, Agustus) dan musim peralihan timur barat (September, Oktober, November) (Ali et al. 2015). Musim penangkapan lobster di Kabupaten Aceh Jaya terjadi produktivitas yang tinggi pada bulan Maret, April dan Mei dimana kondisi saat itu berada pada musim peralihan barat.

Musim penangkapan lobster (Panulirus sp) berlangsung sepanjang tahun, namun ada bulanbulan tertentu yang merupakan musim puncak dan bulan-bulan lainnya musim paceklik (Boesono et al. 2011). Bulan November-Maret merupakan musim penangkapan lobster yang paling baik, hal ini disebabkan pada periode tersebut merupakan awal bertiupnya angin musim barat dan bersamaan dengan turunnya musim penghujan. Musim paceklik terjadi pada bulan Juni-Oktober, hal ini dikarenakan pada periode tersebut bersamaan dengan musim kemarau(Djasmani et al.2012). Meningkatnya hasil tangkapan lobster pada musim hujan juga ditemukan pada P.homarus di Pelabuhanratu dimana terjadi peningkatan di bulan Oktober, November dan tertinggi pada bulan Desember (Permana 2017).Berdasarkan fishing ground lobster, musim penangkapan diawali dari sebelah barat dan bergeser kearah timur yang disebabkan musim hujan bertepatan musim barat menyebabkan air laut bergerak kearah timur. Berkurangnya hasil tangkapan lobster musim kemarau disebabkan kondisi perairan yang lebih dalam menjadi lebih stabil dan ideal untuk kondisi pemijahan. Hal ini disebabkan waktu pemijahan sangat berhubungan dengan suhu. Lobster cenderung bergerak ke perairan yang lebih dalam (37-55m) untuk memijah (Boesono et al.2011).Pemanfaatan lobster di Indonesia sebagian besar berasal dari kegiatan penangkapan. Kegiatan penangkapan lobster yang terus meningkat akan berpengaruh terhadap keseimbangan populasi dan ketersediaan stock lobster di alam (Kadafi et al.2006). Agar pemanfaatan sumberdaya lobster di perairan tetap lestari maka perlu dilakukan pengelolaan yang rasional dengan mempertimbangkan masukan dari aspek biologi (Hargiyatno et al. 2013). 


\section{KESIMPULAN}

1. Komposisi hasil tangkapan lobster yang tertangkap adalah jenis $P$. homarus, $P$. longipes, $P$. ornatus, $P$. penicillatus, $P$. polyphagus, dan $P$. versicolor, dengan didominasi oleh $P$. penicillatus dengan persentase sebesar $34.20 \%$.

2. Kelima jenis lobster $P$. homarus, $P$. longipes, $P$. penicillatus, $P$. versicolor dan $P$. ornatusbersifat allometrik negatif. Hasil tangkapan lobster yang layak tangkap berkisar antara 56.66-100\%, lebih tinggi dibandingkan dengan PERMEN-KP No 56 tahun 2016 dengan ukuran legal tangkap diatas $8 \mathrm{~cm}$ sebesar60.00-90.00\%.

3. Produktivitas penangkapan lobster tertinggi pada tahun 2015-2016 terjadi pada bulan April sebesar $2.440 \mathrm{~kg} /$ trip, dan terendah pada bulan Januari sebesar $1.330 \mathrm{~kg} / \mathrm{trip}$.

\section{SARAN}

Saran yang dapat diberikan yaitu perlu adanya penelitian lebih lanjut tentang hasil tangkapan lobster tahunan melihat aspek sebaran distribusi ukuran dan pola musim penangkapan. Regulasi tentang pembatasan ukuran lobster perlu dikaji ulang berdasarkan ukuran panjang karapas tiap jenis yang berbeda.

\section{UCAPAN TERIMA KASIH}

Penelitian ini dibiayai oleh Lembaga Pengelola Dana Pendidikan (LPDP) Kementerian Keuangan Republik Indonesia. Penelitimengucapkan terimakasih kepada LPDP atas dana penelitian yang diberikan kepada peneliti. Peneliti juga mengucapkan terimakasih kepada pihak-pihak yang terkait atas kerjasamanya selama pengambilan data yaitu Panglima Laot Lhok Rigaih, DKP Kabupaten Aceh Jaya dan nelayan jaring lobster di lokasi penelitian.

\section{DAFTAR PUSTAKA}

Aisyah, Triharyuni S. 2010. Production, size distribution, and length weight relationship of lobster landed in The South Coast of Yogyakarta, Indonesia. Indonesian Fisheries Research Journal. $16(1): 15-24$.

Ali K, Sari TEY, Bustari. 2015. Pengaruh suhu permukaan laut terhadap hasil tangkapan ikan cakalang (Katsuwonus pelamis) di pelabuhan Lampulo Banda Aceh [laporan penelitian]. Aceh (ID). 1-12 hlm.

Bakhtiar E, Boesono H, Sardiyatmo. 2014. Pengaruh perbedaan waktu dan umpan penangkapan lobster (Panulirus sp) dengan alat tangkap krendet (Trap Net) di perairan Watukarung Kabupaten Pacitan. Journal of Fisheries Resources Utilization Management and Technology. 3(3):168-175.

Bal DV, Rao KV. 1984. Marine Fisheries. New Delhi (IN): Gaw-Hill Publishing Company Limited.

Boesono H, Anggoro S, Bambang AN. 2011. Laju tangkap dan analisis usaha penangkapan lobster (Panulirus sp) dengan jaring lobster (Gillnet Monofilament) di perairan Kabupaten Kebumen. Jurnal Saintek Perikanan. 7(1):77-87.

Carpenter EK, Niem VH. 1998. The Living Marine of The Western Central Pacific. FAO Species Identification Guide for Fishery Purposes. Vol II: Cephalopods, Crustaceans, Holothurians, and Sharks. Roma (IT): FAO. 
Chang JY, Sun LC, Chen Y, Yeh ZS, Chiang CW. 2007. Reproductive biology of the spiny lobster, Panulirus penicillatus, in the southeastern coastel waters off Taiwan. Marine Biology. 151(2):553-564.

Dall W. 1974. Indices of nutritional state in the western rock lobster, Panulirus Longipes* (Milne Edwards). I. blood and tissue constituents and water content. Experimental Marine Biology Ecology. 16:167-180.

Djasmani SS, Djumanto, Sukardi. 2012. Pemanfaatan dan laju tangkap udang lobster di Pantai Selatan Daerah Istimewa Yogyakarta. Jurnal Perikanan. 14(1):20-26.

[DKP] Dinas Kelautan dan Perikanan. 2012. Pengendalian dan Pemanfaatan Lobster (Panulirus sp) di Perairan Aceh Jaya dan Simeulu. Aceh (ID): DKP Aceh.

[DKP] Dinas Kelautan dan Perikanan. 2016. Statistik Perikanan Tangkap Provinsi Aceh. Aceh (ID): DKP Aceh.

Fauzi M, Prasetyo AP, Hargiyatno IT, Satria F, Utama AA. 2013. Hubungan panjang-berat dan faktor kondisi lobster batu (Panulirus penicillatus) di perairan selatan Gunung Kidul dan Pacitan. BAWAL. 5(2):97-102.

Febriani PR, Mudzakir AK, Asriyanto. 2014. Analisis CPUE, MSY, dan usaha penangkapan lobster (Panulirus sp.) di Kabupaten Gunungkidul. Journal of Fisheries Resources Utilization Management and Technology. 3(3):208-217.

Frisch AJ. 2007. Population biology and fishery ecology of the painted crayfish, Panulirus versicolor, on the Geet Barrier Reef [thesis]. Australia (AU): James Cook University.

Goddard S. 1996. Feed management in intensive aquaculture. New York (US): Chapman and Hall.

Gomez ED, Juinio MAR, Bermas NA. 1994. Reproduction of Panulirus longipes longipes in Calatagan, Batangas, Philippines. The Philippine Scientist Special Issue Proceeding 3rd Natural Symposium. Marine Science. Philipines. 58-65 hlm.

Hargiyatno IT, Satria F, Prasetyo AP, Fauzi M. 2013. Hubungan panjang-berat dan faktor kondisi lobster pasir (Panulirus homarus) di perairan Yogyakarta dan Pacitan. BAWAL. 5(1):41-48.

Hilal K. 2016. Kepentingan Indonesia melarang ekspor benih lobster ke Vietnam Tahun 2015. JOM FISIP. 3(2).

Holthuis BL. 1991. FAO Species Catalogue. Vol XIII. Rome (IT): FAO.

Ikhwanuddin M, Fatihah NS, Nurul RJ, Zakaria ZM, Munafi BA. 2014. Biological features of mud spiny lobster, Panulirus polyphagus (Herbts, 1793) from Johor coastal water of Malaysia. World Applied Sciences Journal. 31(12):2079-2086.

Junaidi M, Cokrowati N, Abidin Z. 2010. Reproduction aspects of lobster (Panulirus sp.) in Ekas Bay, Lombok Island. Jurnal Kelautan. 3(1):29-36.

Kadafi M, Widaningoem R, Soeparno. 2006. Aspek biologi dan potensi lestari sumberdaya lobster (Panulirus spp.) di perairan Pantai Kecamatan Ayah Kabupaten Kebumen. Jurnal Perikanan. 8(1):108-117.

Kembaren DD, Nurdin E. 2015. Distribusi ukuran dan parameter populasi lobster pasir (Panulirus homarus) di perairan Aceh Barat. BAWAL. 7(3):121-128.

Kulmiye JA, Mavuti MK, Goeneveld CJ. 2006. Size at onset of spiny lobsters Panulirus homarus at Mambrui, Kenya. African Journal of Marine Science. 28(1):121-128. 
Mahdiana A, Laurensia SP. 2013. Status perikanan lobster (Panulirus spp), di perairan Kabupaten Cilacap. Sains Akuatik. 13(2):52-57.

[KKP] Kementrian Kelautan dan Perikanan. 2016. Peraturan Menteri Kelautan dan Perikanan Republik Indonesia Nomor 56/PERMEN-KP/2016 Tentang Larangan Penangkapan Dan/Atau Pengeluaran Lobster (Panulirus spp.), Kepiting (Scylla spp.), dan Rajungan (Portunus spp.) Dari Wilayah Negara Republik Indonesia. Jakarta (ID): KKP.

MertaIGS. 1993. Hubungan panjang-beratdan faktor kondisi ikan lemuru, Sardinella lemuru Bleeker, 1853 dari perairan Selat Bali. Jurnal.Penelitian Perikanan Laut. (73):35-44.

Moutopoulos DK, Stergiou KI. 2002. Length-weight and length-length relationships of fish species from the Aegean Sea (Greece). Journal of Applied Ichthyology. 18(3):200-203.

Nevada HAT, Martasuganda S, Zulbainami N, Dirwana I. 2012. Pengaruh perbedaan atraktor terhadap hasil tangkapan juvenil lobster dengan korang di desa Sangrawayan, Palabuhanratu. Marine Fisheries. 3(2):129-133.

Nurdin E, Taufik, Rizal M, Jaliadi, Iskandar T, Anhar. 2014. Kondisi udang di perairan Aceh Barat dan Aceh Jaya. [Laporan Penelitian]. Jakarta (ID): Balai Riset Perikanan Laut.

Page J. 2013. First record of the painted spiny lobster Panulirus versicolor (Latrielle, 1804) in coastal Georgia, USA. BioInvasions Records (REABIC). 2(2):149-152.

Permana A. 2017. Kegiatan penangkapan lobster hijau pasir (Panulirus homarus, Linnaeus 1758) berkelanjutan di teluk Palabuhanratu [tesis]. Bogor (ID): Institut Pertanian Bogor.

Saputra SW. 2009. Status pemanfaatan lobster (Panulirus sp) di perairan Kebumen. Jurnal Saintek Perikanan. 4(2):10-15.

Sparre P, Venema SC. 1999. Introduksi Pengkajian Stok Ikan Tropis. Terjemahan dari Introduction to Tropical Fish Stock Assesment. Jakarta (ID): Pusat Penelitian dan Pengembangan Perikanan.

Suadi, Widaningroem R, Soeparno, Probosunu N. 2001. Kajian sumber daya lobster di pantai selatan Daerah Istimewa Yogyakarta. Jurnal Ilmu-Ilmu Perairan dan Perikanan Indonesia. 1(2):33-42.

Suman A, Subani W. 1993. Pengusahaan sumberdaya udang karang di perairan Aceh Barat. Jurnal Penelitian Perikanan Laut. (81):84-90.

SumanA, Subani W, Prahoro P. 1994. Beberapa parameter biologi udang pantung (Panulirus homarus) di perairan Pangandaran Jawa Barat. Jurnal Penelitian Perikanan Laut (85):1-8.

Tewfik A, Mills D, Adhuri D. 2009. Spiny resoursces and opportunity for culture in post-tsunami Aceh, Indonesia. In: Williams KC. (ed) Spiny lobster aquaculture in the Asia-Pacific region. Procedings of an international symposium; 2008 Dec 9-10; Nha Trang, Vietnam (VN): ACIAR.

Yusnaini, Nessa NM, Djawad IM, Trijuno DD. 2009. Ciri morfologi jenis kelamin dan kedewasaan lobster mutiara (Panulirus ornatus). Jurnal Ilmu Kelautan dan Perikanan. 19(3):166-174.

Zakaria ZM, Kassim A. 1999. Size at maturity stages of lobster, Panulirus ornatus Fabricus. Proceding seminar University Putra Malaysia Terengganu. Kuala Terengganu. Malaysia (MY). 